\title{
Cystic Lymphangioma of the Pancreas with Spontaneous Rupture: Report of a Case
}

\author{
Kei Kawaguchia Fuyuhiko Motoi ${ }^{a}$ Hideo Ohtsuka ${ }^{a}$ \\ Shoji Fukuyama ${ }^{a}$ Toshiki Rikiyama $^{a}$ Yu Katayose $^{a}$ \\ Shinichi Egawa ${ }^{a}$ Masahiro Satoh $^{c}$ Toru Asakurab $^{b}$ \\ Toru Shimosegawa $^{\mathrm{b}}$ Michiaki Unno ${ }^{\mathrm{a}}$
}

Departments of a Gastroenterological Surgery and ${ }^{b}$ Gastroenterology, Graduate School of Medicine, Tohoku University, Sendai, and 'Department of

Gastroenterology, Hachinohe Shimin Hospital, Hachinohe, Japan

\section{Key Words}

Lymphangioma $\cdot$ Pancreas $\cdot$ Rupture $\cdot$ D2-40

\begin{abstract}
Lymphangioma is a benign and congenital malformation of the lymphatic system. Most lymphangiomas are preferentially located in the head and neck region. The abdominal organs are uncommon sites of origin. Several cases of lymphangioma in abdominal organs were reported, however, the pancreas is one of the rarest origins. Generally, intra-abdominal lymphangioma is asymptomatic and found incidentally, but in some cases, the patient complains of abdominal distension or a palpable mass. We describe the case of a 38-year-old male who presented with sudden-onset upper abdominal pain. Rupture of a cystic tumor of the pancreatic head was suspected, based on the findings of computed tomography, magnetic resonance imaging and endoscopic ultrasonography. Subtotal stomach-preserving pancreaticoduodenectomy was undertaken. The tumor, which was $4 \times 4.5 \times 8 \mathrm{~cm}$ in size, was pathologically diagnosed as a cystic lymphangioma. In conclusion, pancreatic lymphangioma is mostly asymptomatic, a ruptured case causing 'acute abdomen' has never been reported. Since lymphangioma is benign, it could be observed with accurate diagnosis. The surgical indication would be limited to cases of symptomatic lymphangiomas.
\end{abstract}




\section{Introduction}

Lymphangiomas are benign and congenital malformations of the lymphatic system. They are most common in children and found frequently in the neck and axilla (95\%), but have also been reported to occur in other sites including bone, scrotum, penis, cervix, fallopian tubes, and broad ligament $[1,2]$. The abdominal organs are uncommon sites of origin, and most cases have been reported to be in the retroperitoneum or mesentery. Several cases of lymphangioma in abdominal organs were reported, however, pancreatic lymphangioma is quite rare. Herein we report a case of ruptured lymphangioma causing acute abdomen, arising from the pancreas, successfully treated with surgical intervention. Although it is considered as a benign lesion, surgery must take into account the varying cases.

\section{Case Report}

A 38-year-old male presented with sudden-onset upper abdominal pain. He was otherwise in good health with no history of any similar pain. The patient visited the emergency room at another clinic, and physical findings on admission revealed neither abdominal mass nor tenderness. Laboratory data were all within normal limits. Abdomino-pelvic computed tomography showed a multicystic mass in the pancreatic head without dilatation of the main pancreatic duct or the common bile duct, which was $5 \times 8 \mathrm{~cm}$ in size. Accumulation of ascites was not detected (fig. 1a). Magnetic resonance imaging of the abdomen demonstrated a multicystic legion at the para-duodenum, retroperitoneum, and the pancreatic head. Those cyst walls were slightly enhanced with gadolinium (fig. 1b). From these radiographic findings, lymphangioma, serous cystadenoma, intraductal papillary mucinous neoplasm, mucinous cystic tumor, lymphoepithelial cyst, pseudocyst etc. were suspected.

Under consideration of the clinical course, compatible with rupture of the cystic tumor of the pancreatic head, he was transferred to our hospital for further medical examination and treatment. After the patient had been transferred to our hospital, endoscopic ultrasonography (EUS) was performed. EUS showed multilocular cysts of the pancreatic head involving the gallbladder and duodenum, which indicated lymphangioma (fig. 1c). On the next day, subtotal stomach-preserving pancreaticoduodenectomy was undertaken under general anesthesia. A multichamber cystic tumor, $4 \times 4.5 \times 8 \mathrm{~cm}$ in size, was encircled the by duodenum and pancreas head. Its contents were cloudy purulent fluid and this fluid collected around the lesion. It seemed that part of the contents was leaking from the lesion and attached to the surface of the pancreas. This fluid was removed as soon as practicable. These findings indicated that the cystic tumor had ruptured. The margin between the tumor and the pancreas was indistinct, and the tumor seemed to originate from the pancreas. The tumor was totally removed with the duodenum and the pancreas (fig. 2). The cyst lesion was closed and attached, but did not involve the gallbladder in the intraoperative findings. Histologically, the multicystic lesion was composed of an irregularly dilated space separated by fibrous tissue and smooth muscle fascicle. The cyst wall was lined by lymphatic endothelial cells. Immunohistochemically, D2-40 was partially positive in the cyst wall and negative endothelial cells were also observed (fig. 3 ). From the findings above, it was diagnosed as a cystic lymphangioma of the pancreas. The postoperative course was uneventful and the patient was discharged 14 days after the operation.

\section{Discussion}

Pancreatic lymphangioma is a very rare entity. Since 1913, when Koch reported the first case [3], 56 cases were reported until 2005 [4, 5]. Since then, 11 further cases have been reported in the world literature, including the present case (table 1). Thus we can review 67 cases of pancreatic lymphangioma. There were more women than men (46:21) and the patients ranged in age from 2 to 81 years (mean age 43.1 years). The initial clinical 
symptoms are variable and may include abdominal pain, nausea, vomiting and a palpable abdominal mass. However, many patients were asymptomatic.

In the literature, some cases were treated with surgical procedures. However lymphangioma is considered as a benign entity. When a diagnosis of pancreatic lymphangioma is made in an asymptomatic patient, surgery should be avoided. EUS-guided fine needle aspiration (EUS-FNA) is invaluable for the assessment of cystic lesions of the pancreas. EUS-FNA is a safe and accurate method for diagnosis, evaluation and treatment $[6,7]$. The case presented here was surgically treated because of acute abdomen with a strong suspicion of rupture of the cyst. If EUS-FNA had been performed, it could have triggered re-rupture. It is true that EUS-FNA is a useful modality, however, for cases with suspected rupture, adaptation of EUS-FNA should be considered carefully. Treatment for asymptomatic cystic lymphangiomas is still controversial. Surgical removal with close inspection is strongly proposed when the patient has any symptoms. Since the lesion was located in the pancreas head and pancreatic duct and common bile duct was involved, pancreaticoduodenectomy was carried out and clinical outcome was excellent.

The most popular theory concerning the pathogenesis of lymphangioma is abdominal development of the lymphatic system in the dorsal mesoduodenum during the second and third month of fetal life. Histologically, lymphangiomas are divided into three subgroups; capillary type, cavernous type and cystic type [8]. Among them, cystic lymphangioma is the most common. Typically, it arises from the pancreas body rather than the pancreas head [9], and it seems difficult to differentiate from the other cystic neoplasms of the pancreas by imaging since they all have the appearance of multilocular cysts [10-12]. In our case, the lymphangioma was located in the pancreas head without obstruction of the main pancreatic duct or the common bile duct. Those findings made us conclude that this lesion was benign and not invasive.

Histopathological findings were typical of cystic lymphangioma. It was mostly composed of multicystic component delineated with a thin endothelial layer [11]. Those endothelial cells showed positive staining for D2-40, which is a sensitive, specific and reliable markers for the identification of lymphatic and capillary endothelium [13, 14]. No proliferation feature such as mitosis was detected. Although in literature genetic alteration in the VEGFR-3 gene was reported to be more specific for this entity [15], it was not available in our case. Further analysis is necessary to obtain a detailed diagnosis.

We present here a patient with lymphangioma diagnosed with multimodality methods, resulting in correct timing for surgical treatment. Further follow-up is necessary, however the clinical course was favorable. Although lymphangioma is pathologically benign, surgical removal should be the first choice for symptomatic lymphangiomas. 


\begin{tabular}{r|l|l|l}
$\begin{array}{r}\text { Case Reports in } \\
\text { Gastroenterology }\end{array}$ & $\begin{array}{l}\text { Case Rep Gastroenterol 2011;5:288-294 } \\
\text { Dol: 10.1159/000326943 }\end{array}$ & $\begin{array}{l}\text { Published online: } \\
\text { May 24, 2011 }\end{array}$ & $\begin{array}{l}\text { O 2011 S. Karger AG, Basel } \\
\text { ISSN 1662-0631 } \\
\text { www.karger.com/crg }\end{array}$ \\
\hline
\end{tabular}

Table 1. Cases of pancreatic lymphangioma reported since 2005

\begin{tabular}{|c|c|c|c|c|c|c|c|}
\hline Reference & Age & Sex & Symptoms & $\begin{array}{l}\text { Tumor } \\
\text { location }\end{array}$ & $\begin{array}{l}\text { Size } \\
(\mathrm{cm})\end{array}$ & Treatment & $\begin{array}{l}\text { His- } \\
\text { tology }\end{array}$ \\
\hline Present report & 38 & M & $\begin{array}{l}\text { upper abdominal pain due } \\
\text { to rupture }\end{array}$ & head & $4 \times 4.5 \times 8$ & $\mathrm{PD}$ & cystic \\
\hline Colovic et al. [16] & 49 & $\mathrm{~F}$ & upper abdominal pain & body & $3.5 \times 3.5$ & complete excision & cystic \\
\hline Lyngdoh et al. [17] & middle-aged & $\mathrm{F}$ & diffuse abdominal swelling & tail & $32 \times 28$ & complete excision & cystic \\
\hline Sanaka et al. [18] & 46 & $\mathrm{~F}$ & no detailed information & body & $6.0 \times 2.5$ & EUS-FNA & cystic \\
\hline \multirow[t]{2}{*}{ Applebaum et al. [19] } & 70 & M & no detailed information & head & $4.6 \times 2.7$ & EUS-FNA & cystic \\
\hline & 63 & $\mathrm{~F}$ & no detailed information & uncinate & $3.7 \times 2.6$ & EUS-FNA & cystic \\
\hline Leung et al. [12] & 34 & $\mathrm{~F}$ & asymptomatic & tail & $6 \times 6$ & extirpation & cystic \\
\hline Goh et al. [20] & 62 & $\mathrm{~F}$ & $\begin{array}{l}\text { upper abdominal pain, } \\
\text { body weight loss }\end{array}$ & head & $4 \times 5$ & biopsy & cystic \\
\hline Nobuhara et al. [5] & 47 & $\mathrm{~F}$ & asymptomatic & head & $5 \times 10$ & biopsy & cystic \\
\hline
\end{tabular}

$\mathrm{PD}=$ Pancreatoduodenectomy
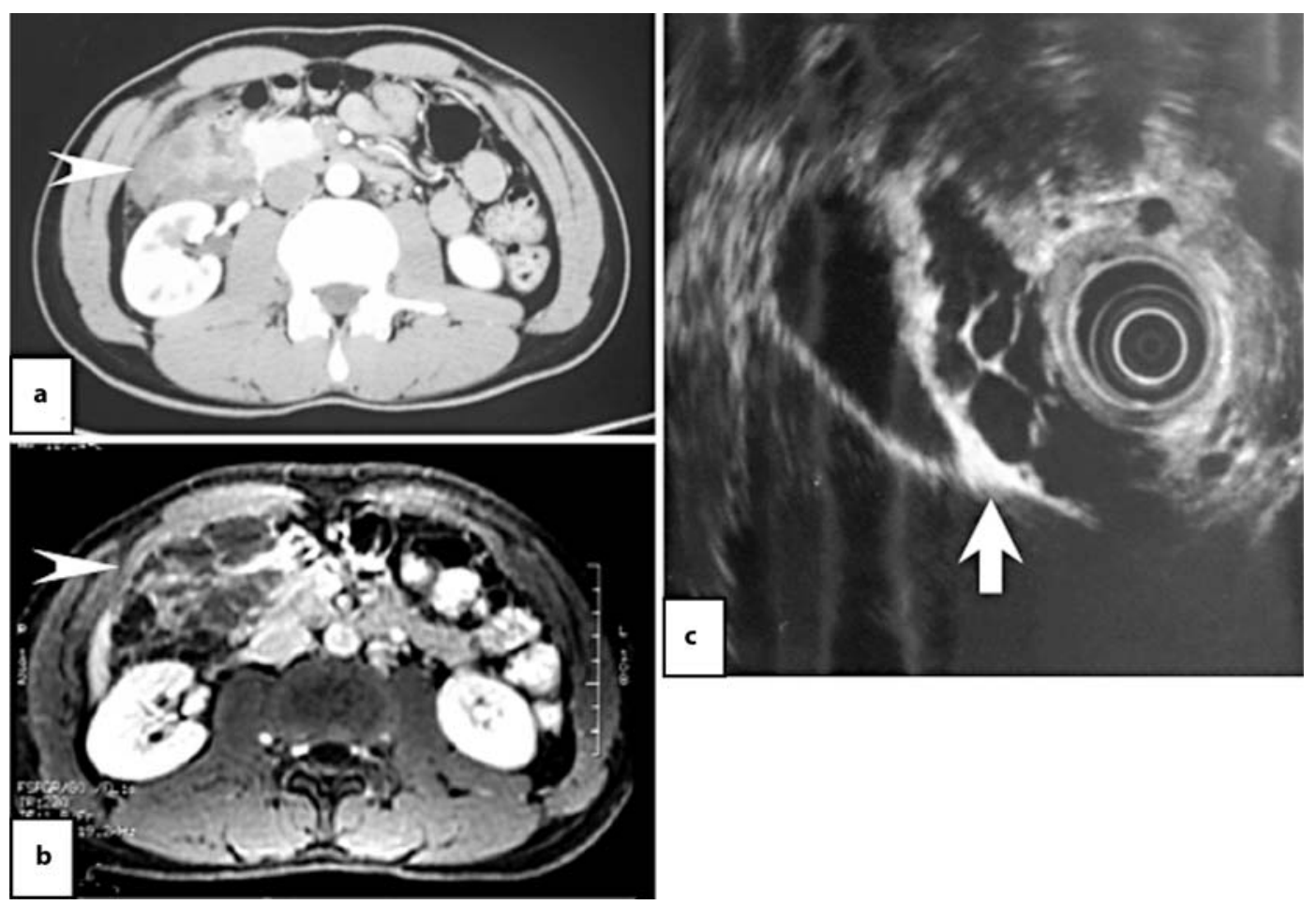

Fig. 1. Radiographic findings. a Computed tomography revealed a mass $8.1 \times 5.3 \mathrm{~cm}$ in size occupying the region of the duodenum, retroperitoneum and pancreas (arrowhead). $\mathbf{b}$ T1-weighted magnetic resonance imaging with gadolinium showed a multicystic legion with slight enhancement in the region of the duodenum, retroperitoneum and pancreatic head (arrowhead). c EUS showed multilocular cysts among the pancreatic head, gallbladder and duodenum (arrow). 


\begin{tabular}{|c|c|c|c|}
\hline $\begin{array}{r}\text { Case Reports in } \\
\text { Gastroenterology }\end{array}$ & $\begin{array}{l}\text { Case Rep Gastroenterol 2011;5:288-294 } \\
\text { DOI: 10.1159/000326943 }\end{array}$ & \begin{tabular}{|l} 
Published online: \\
May 24, 2011
\end{tabular} & $\begin{array}{l}\text { O } 2011 \text { S. Karger AG, Basel } \\
\text { ISSN 1662-0631 } \\
\text { www.karger.com/crg }\end{array}$ \\
\hline
\end{tabular}

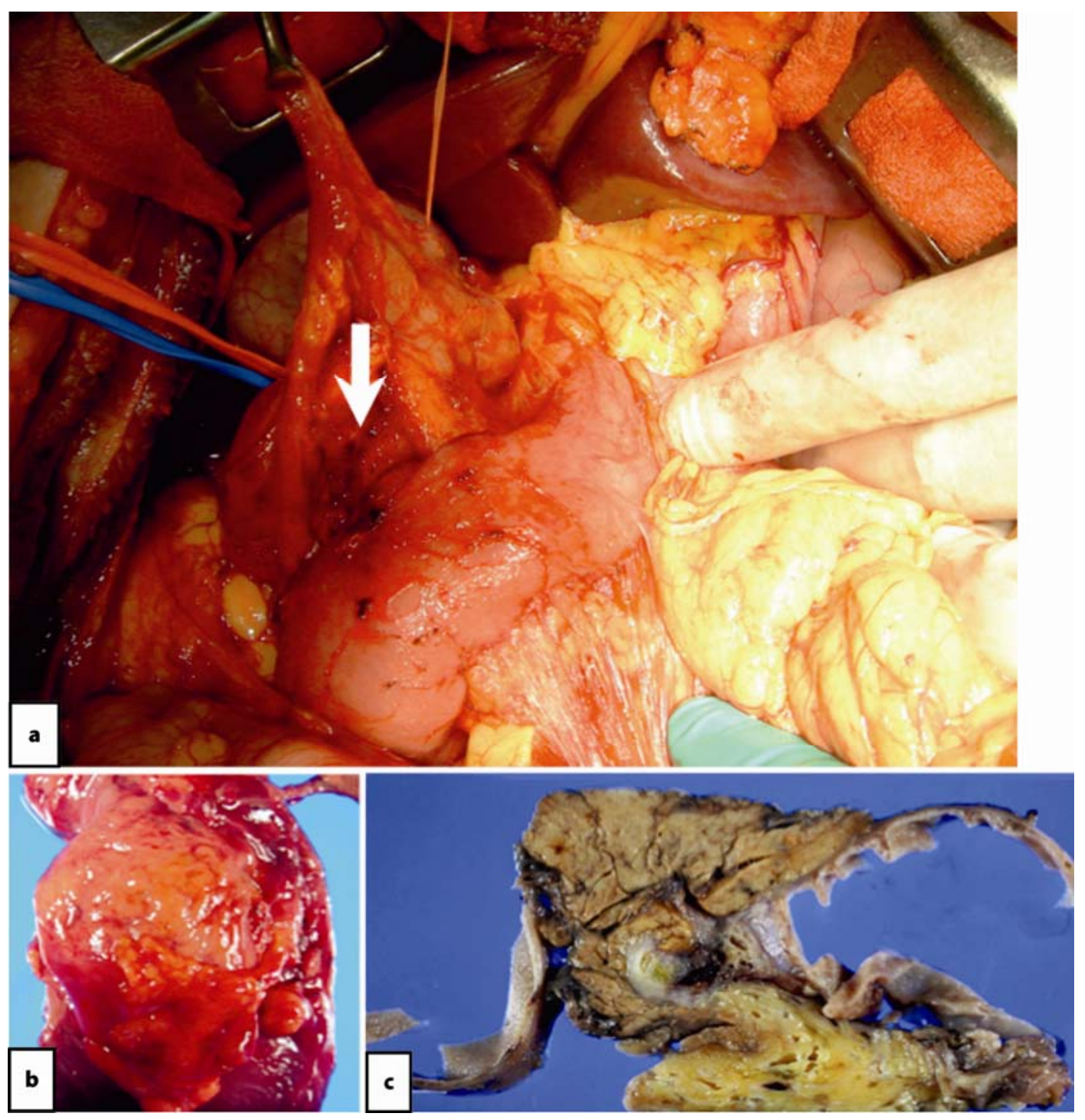

Fig. 2. a Intraoperative finding showing the ruptured lymphangioma of the pancreas head (arrow). b The excised mass. c Formalin-fixed cystic wall after sectioning. 


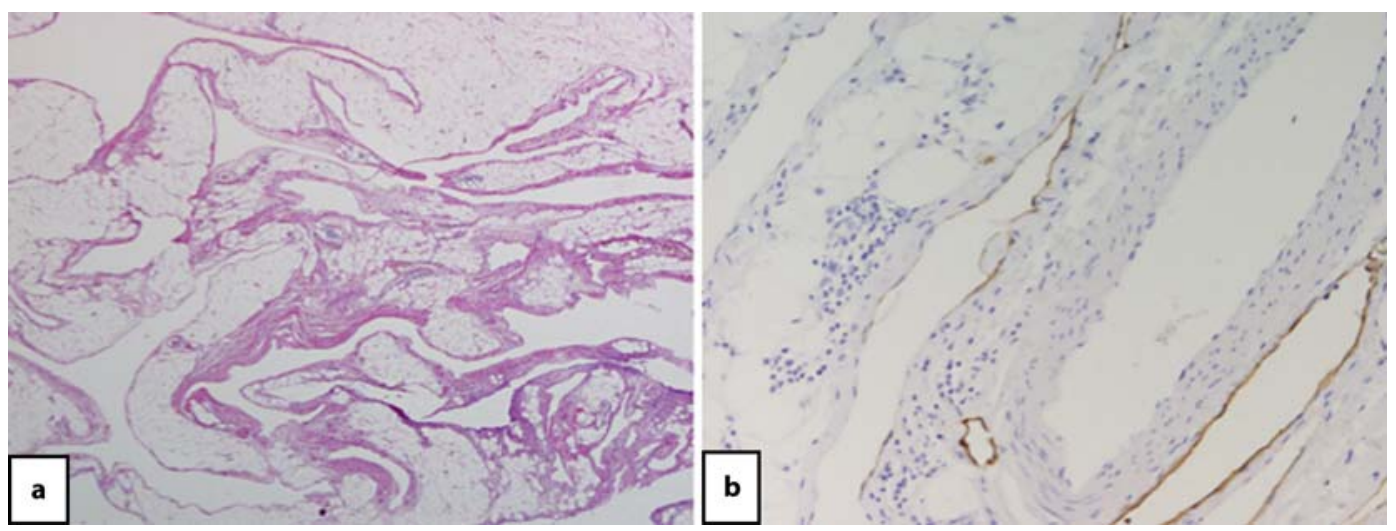

Fig. 3. Histological findings. a Hematoxylin and eosin staining showed that the multicystic lesion was composed of an irregularly dilated space separated by fibrous tissue and smooth muscle fascicle. The wall of the cyst was lined by a layer of lymphatic endothelial cells. Those endothelial cells showed partially positive staining for D2-40 (b).

\section{References}

1 Khandelwal M, Lichtenstein GR, Morris JB, et al: Abdominal lymphangioma masquerading as a pancreatic cystic neoplasm. J Clin Gastroenterol 1995;20:142-144.

2 Singh S, Baboo ML, Pathak IC: Cystic lymphangioma in children: report of 32 cases including lesions at rare sites. Surgery 1971;69:947-951.

3 Koch K: Beiträge zur Pathologie der Bauchspeicheldrüse. Virchows Arch [A] 1913;214:180-206.

$\checkmark 4$ Igarashi A, Maruo Y, Ito T, et al: Huge cystic lymphangioma of the pancreas: report of a case. Surg Today 2001;31:743-746.

5 Nobuhara Y, Onoda N, Fukai K, et al: TIE2 gain-of-function mutation in a patient with pancreatic lymphangioma associated with blue rubber-bleb nevus syndrome: report of a case. Surg Today 2006;36: 283-286.

6 Dries AM, McDermott J: Diagnosis of cystic lymphangioma of the pancreas with endoscopic ultrasoundguided fine needle aspiration. Am J Gastroenterol 2008;103:1049-1050.

7 Jathal A, Arsenescu R, Crowe G, et al: Diagnosis of pancreatic cystic lymphangioma with EUS-guided FNA: report of a case. Gastrointest Endosc 2005;61:920-922.

8 Asch MJ, Cohen AH, Moore TC: Hepatic and splenic lymphangiomatosis with skeletal involvement: report of a case and review of the literature. Surgery 1974;76:334-339.

9 Gui L, Bigler SA, Subramony C: Lymphangioma of the pancreas with 'ovarian-like' mesenchymal stroma: a case report with emphasis on histogenesis. Arch Pathol Lab Med 2003;127:1513-1516.

10 Procacci C, Biasiutti C, Carbognin G, et al: Characterization of cystic tumors of the pancreas: CT accuracy. J Comput Assist Tomogr 1999;23:906-912.

11 Gray G, Fried K, Iraci J: Cystic lymphangioma of the pancreas: CT and pathologic findings. Abdom Imaging 1998;23:78-80.

12 Leung TK, Lee CM, Shen LK, Chen YY: Differential diagnosis of cystic lymphangioma of the pancreas based on imaging features. J Formos Med Assoc 2006;105:512-517.

13 Hornick JL, Fletcher CD: Intraabdominal cystic lymphangiomas obscured by marked superimposed reactive changes: clinicopathological analysis of a series. Hum Pathol 2005;36:426-432.

14 Kalof AN, Cooper K: D2-40 immunohistochemistry - so far! Adv Anat Pathol 2009;16:62-64.

15 Norgall S, Papoutsi M, Rossler J, et al: Elevated expression of VEGFR-3 in lymphatic endothelial cells from lymphangiomas. BMC Cancer 2007;7:105.

16 Colovic RB, Grubor NM, Micev MT, Atkinson HD, Rankovic VI, Jagodic MM: Cystic lymphangioma of the pancreas. World J Gastroenterol 2008;14:6873-6875.

17 Lyngdoh TS, Konsam R, Th B, Marak B: Giant cystic lymphangioma of pancreas. ANZ J Surg 2008;78:673-674. 
18 Sanaka MR, Kowalski TE: Cystic lymphangioma of the pancreas. Clin Gastroenterol Hepatol 2007;5:e10-e11.

19 Applebaum B, Cunningham JT: Two cases of cystic lymphangioma of the pancreas: a rare finding in endoscopic ultrasonography. Endoscopy 2006;38(suppl 2):E24-E25.

20 Goh BK, Tan YM, Ooi LL: Hepatobiliary and pancreatic: cystic lymphangioma of the pancreas. J Gastroenterol Hepatol 2006;21:618. 